\title{
TRATAMENTO DE ELETROCOAGULAÇÃO PARA A REMOÇÃO DE POLUENTES NA ÁGUA DE PROCESSAMENTO DE MAÇÃS
}

\author{
GAMBA, V. ${ }^{1}$, CARPES, V. M. ${ }^{2}$ e HEMKEMEIER, M. ${ }^{3}$ \\ ${ }^{1}$ Universidade de Passo Fundo, Faculdade de Engenharia Química. \\ ${ }^{2}$ Universidade de Passo Fundo, Programa de Pós Graduação em Ciência e Tecnologia de \\ Alimentos. \\ ${ }^{3}$ Universidade de Passo Fundo, Faculdade de Engenharia e Arquitetura. \\ E-mail para contato: 150817@upf.br
}

\begin{abstract}
RESUMO - O sistema de filtração tradicionalmente empregado para o tratamento de água em indústrias de processamento de maçãs, geralmente não é capaz de aumentar o ciclo de vida útil da água no processo. O ciclo de uso dessa água é reduzido, devido às alterações físico-químicas que ocorrem durante o processo industrial. Diante deste cenário, os empreendimentos realizam o descarte contínuo de elevados volumes de água. Sendo assim, a implantação de um sistema de tratamento de água eficiente, pode proporcionar a redução nas vazões de captação e lançamento. A ausência de reagentes químicos, baixa geração de lodo e a compactação do tratamento, tornam a eletrocoagulação (EC), uma tecnologia limpa e promissora na área de tratamento de águas e efluentes com carga orgânica reduzida, sendo uma alternativa para a substituição de sistemas de tratamentos físico-químicos convencionais. O presente trabalho teve como principal objetivo, propor um tratamento de EC avaliando a influência dos fatores: tempo de detenção hidráulica (TDH) e agitação mecânica do sistema, para a remoção de poluentes da água utilizada na cadeia produtiva de maçãs. A aplicação do tratamento de EC apresentou diferentes porcentagens de eficiência na remoção de interferentes físico-químicos nas condições experimentais, podendo estabelecer a sustentabilidade hídrica destes empreendimentos, proporcionando alívio na demanda de água, minimizando os impactos ambientais e os custos operacionais de processo.
\end{abstract}

\section{1. ÁGUA DE PROCESSAMENTO DE INDÚTRIA DE MAÇÃS}

As indústrias de processamento de maçãs utilizam altas vazões de água com qualidade potável nas calhas para o transporte e higienização das maçãs, a qual é continuamente contaminada com fungos, cor, turbidez e matéria orgânica.

A deterioração dessa água de processamento compromete a qualidade da mesma, e como consequência, frequente e elevado descarte dessa água. Seu tempo de residência no processo representa um grave risco para a qualidade fisiológica, metabólica, sensorial e sanitária das maçãs, visto que por meio dessas lesões mecânicas pode haver a disseminação de doenças fúngicas.

As características da água de processo variam conforme a época e quantidade de produto processado, visto que, em épocas de maior residência dessa água dentro da planta industrial, 
ocorre uma maior viabilidade de contaminação fúngica, concentração de poluentes e material biodegradável.

\subsection{Caracterização}

As características da água de processamento foram avaliadas durante o ano e coletadas em alternados períodos da colheita e posterior processamento das maçãs. Diante dessa caracterização físico-química e microbiológica, é possível determinar que, em períodos onde a residência dessa água for maior na planta industrial, a contaminação fúngica e a carga orgânica podem influenciar diretamente na qualidade e potabilidade dessa água.

Por apresentar baixa carga orgânica, o estudo da remoção desses poluentes pelo princípio do tratamento eletrolítico foi avaliado, a fim de aumentar o ciclo de vida útil da água de processamento.

\section{ELETROCOAGULAÇÃ̃O}

A eletrocoagulação (EC) é um processo de tratamento eletroquímico em que é aplicada uma corrente contínua entre eletrodos de metal, imersos em água e utiliza ânodos solúveis (consumíveis) feitos geralmente de ferro (Fe) ou alumínio (Al). Com a dissolução eletrolítica de íons metálicos dissolvidos, $\mathrm{Al}^{3+}$ e $\mathrm{Fe}^{2+}$, pode haver a formação de uma vasta gama de espécies de coagulantes e hidróxidos poliméricos, que desestabilizam e agregam as partículas em suspensão ou precipitam e adsorvem os contaminantes dissolvidos em água (CHEN, 2004; MOLLAH et al., 2004; MATILAINEN; VEPSÄLÄINEN; SILLANPÄ̈̈, 2010).

$\mathrm{Na}$ EC os íons de coagulação são produzidos "in situ" e envolve três etapas sucessivas: $\left.1^{a}\right)$ formação de coagulantes por oxidação eletrolítica do "eletrodo de sacrifício"; $2^{\mathrm{a}}$ ) a desestabilização das partículas contaminantes em suspensão e a quebra de emulsões; $3^{\text {a }}$ ) agregação das fases desestabilizadas para formação de flocos (CHEN, 2004; MERZOUK; MADANI; SEKKI, 2010; MOLLAH et al., 2004; TANNERU; CHELLAM, 2012). Os ânodos de metal consumíveis ("eletrodo de sacrifício" ou eletrodo dissociável) são usados para produzir continuamente hidróxidos poliméricos na vizinhança do ânodo (MOLLAH et al., 2004; RAJKUMAR; PALANIVELU, 2004).

Em um sistema de EC o conjunto de eletrodos é geralmente ligado a uma fonte de corrente contínua externa, que aplica uma diferença de potencial para os eletrodos de metal, ocorrendo à formação de um campo elétrico entre eles (MOLLAH et al., 2004). A geração de íons metálicos ocorre no ânodo e a partir do cátodo há a liberação do gás hidrogênio $\left(\mathrm{H}^{2}\right)$. $\mathrm{O}$ gás hidrogênio tem o papel de auxiliar as partículas floculadas a flutuarem no tratamento de água e este processo é chamado de eletroflotação (CHEN, 2004).

Dessa forma, os íons de carga positiva (cátions) se movimentam em direção ao cátodo (eletrodo de carga negativa) e os ânions se movimentam em direção ao ânodo (eletrodo de carga positiva). Assim, os íons são neutralizados eletricamente nos eletrodos. A quantidade de metal depositado ou dissolvido é dependente da quantidade de eletricidade que passa através da solução eletrolítica (CHEN, 2004; MOLLAH et al., 2004; TANNERU; CHELLAM, 2012). 
A ausência de reagentes químicos, baixa geração de lodo e compactação do processo, tornam a eletrocoagulação (EC), uma tecnologia limpa e promissora na área de tratamento de águas e efluentes com carga orgânica reduzida, sendo uma alternativa para a substituição de sistemas de tratamentos físico-químicos convencionais.

O presente trabalho teve como principal objetivo, propor um tratamento de EC avaliando a influência dos fatores: tempo de detenção hidráulica (TDH) e agitação mecânica do sistema, para a remoção de poluentes da água utilizada na cadeia produtiva de maçãs.

\subsection{Tratamento Eletrolítico de Eletrocoagulação}

Para o tratamento de EC, utilizou-se um reator eletrolítico composto por cuba eletrolítica (béquer de 2,0 L), banho termostático, fonte de corrente contínua, conectores elétricos, sistema de agitação mecânica e um conjunto de eletrodos de aço carbono (cátodo) com área de $6,40 \times 10^{-3} \mathrm{~m}^{2}$ e o ânodo de alumínio com área de 5,20 x $10^{-3} \mathrm{~m}^{2}$, dispostos verticalmente no reator. $\mathrm{O}$ espaçamento entre os eletrodos foi mantido constante $(10 \mathrm{~mm})$. $\mathrm{O}$ tratamento de EC foi realizado sob condições galvanostáticas e foram mantidos constantes a densidade de corrente $\left(20 \mathrm{~A} / \mathrm{m}^{2}\right), \mathrm{pH}(6,00)$ e temperatura $\left(20^{\circ} \mathrm{C}\right)$. A Figura 1 apresenta o arranjo vertical dos eletrodos e a haste de agitação mecânica.

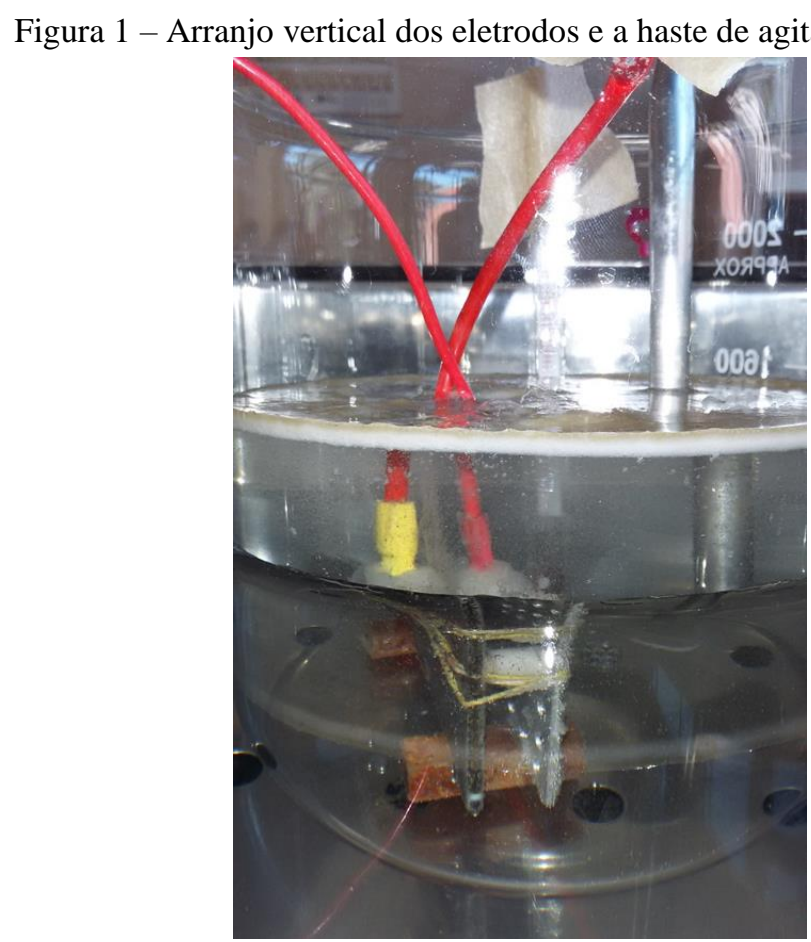

Fonte: Autor (2016).

As variáveis independentes descritas na Tabela 1, foram TDH de 20 e 40 minutos e agitação do sistema de 0 e 40 rotações por minuto (rpm). Os fatores de resposta foram a remoção dos poluentes: Matéria Orgânica (MO), Demanda Química de Oxigênio (DQO), Sólidos Suspensos Totais (SST), turbidez e cor. 
Tabela 1 - Tratamento sobre influência das variáveis independentes

\begin{tabular}{ccc} 
ENSAIO & TDH (min). & Agitação (rpm). \\
\hline 1 & 20 & 0 \\
2 & 40 & 0 \\
3 & 20 & 40 \\
4 & 40 & 40 \\
\hline \multicolumn{2}{c}{ Fonte: Elaborado pelo Autor (2016). }
\end{tabular}

\section{RESULTADOS}

A Tabela 2 expõe a eficiência de remoção dos poluentes obtidos pelo tratamento de EC.

Tabela 2 - Eficiência de remoção dos poluentes

\begin{tabular}{cccccc}
\hline \multirow{2}{*}{ ENSAIO } & \multicolumn{5}{c}{ Eficiência (\% de remoção) } \\
\cline { 2 - 6 } & MO & DQO & SST & Turbidez & Cor \\
\hline 1 & $14,81 \pm 7,85^{\mathrm{a}}$ & $34,64 \pm 1,97^{\mathrm{d}}$ & $74,16 \pm 1,98^{\mathrm{a}}$ & $53,93 \pm 1,95^{\mathrm{a}}$ & $24,19 \pm 2,79^{\mathrm{a}}$ \\
2 & $44,45 \pm 9,00^{\mathrm{b}}$ & $42,69 \pm 1,00^{\mathrm{b}}$ & $80,21 \pm 0,26^{\mathrm{b}}$ & $73,02 \pm 5,83^{\mathrm{bc}}$ & $51,61 \pm 0,0^{\mathrm{b}}$ \\
3 & $46,15 \pm 7,69^{\mathrm{b}}$ & $64,28 \pm 1,51^{\mathrm{c}}$ & $86,75 \pm 2,29^{\mathrm{c}}$ & $70,78 \pm 1,95^{\mathrm{c}}$ & $53,21 \pm 2,77^{\mathrm{b}}$ \\
4 & $55,56 \pm 9,62^{\mathrm{b}}$ & $80,86 \pm 2,01^{\mathrm{d}}$ & $90,06 \pm 1,98^{\mathrm{c}}$ & $79,77 \pm 0,0^{\mathrm{b}}$ & $67,74 \pm 2,79^{\mathrm{c}}$ \\
\hline
\end{tabular}

Resultados expressos como média de três determinações \pm desvio padrão. Valores seguidos de letras diferentes na mesma coluna diferem-se pelo Teste de Tukey $(\mathrm{p}<0,05)$.

Fonte: Elaborado pelo Autor (2016).

Conforme os resultados expostos na Tabela 2, observa-se que a aplicação do tratamento de EC apresentou as melhores eficiências na remoção dos poluentes, pelo Teste de Tukey, nas condições experimentais de TDH de 40 minutos e agitação de $40 \mathrm{rpm}$. Essas condições auxiliaram na homogeneização e transporte do coagulante formado pelo ânodo de alumínio, que gerou a neutralização das cargas superficiais das partículas coloidais e suspensas dos contaminantes dissolvidos em água, desestabilizando-as. A aglutinação dessas partículas desestabilizadas pelos hidróxidos metálicos proporcionou então, a formação dos flocos. Simultaneamente, as microbolhas de gás oxigênio geradas no ânodo e de gás hidrogênio geradas no cátodo, formadas pela hidrólise da água, ascenderam à superfície por eletroflotação, carregando por arraste, os flocos formados, promovendo assim, a remoção dos poluentes (CAN, 2014; XU et al., 2015) como pode ser visto na Figura 2.

Figura 2 - Lodo na superfície do tratamento de EC

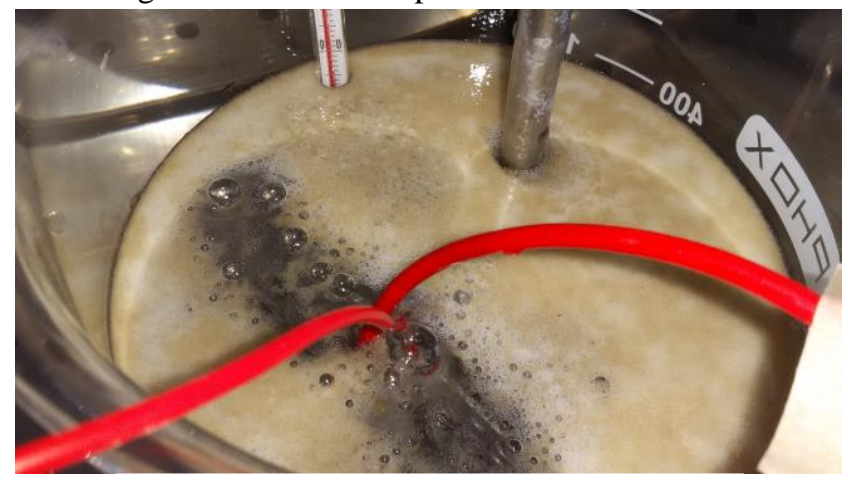

Fonte: Autor (2016). 
A remoção de cor e turbidez pode ser observada nas Figuras 3 e 4, onde houve a clarificação da água após o tratamento de EC.

Figura 3 - Antes do tratamento de EC

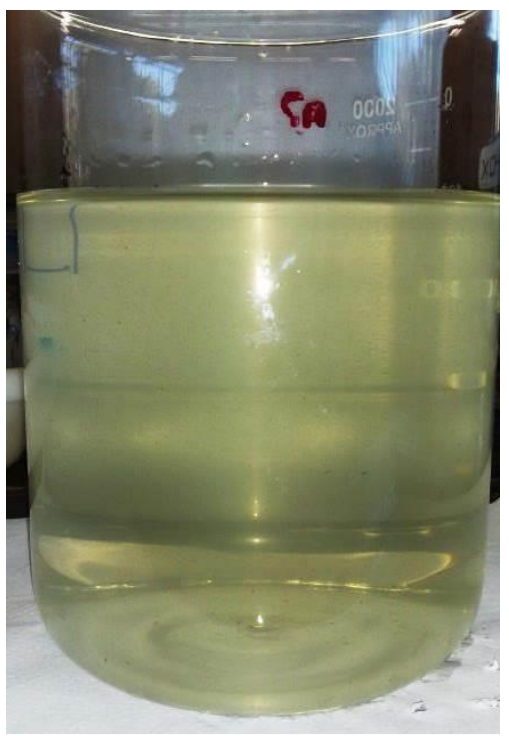

Fonte: Autor (2016).
Figura 4 - Após o tratamento de EC

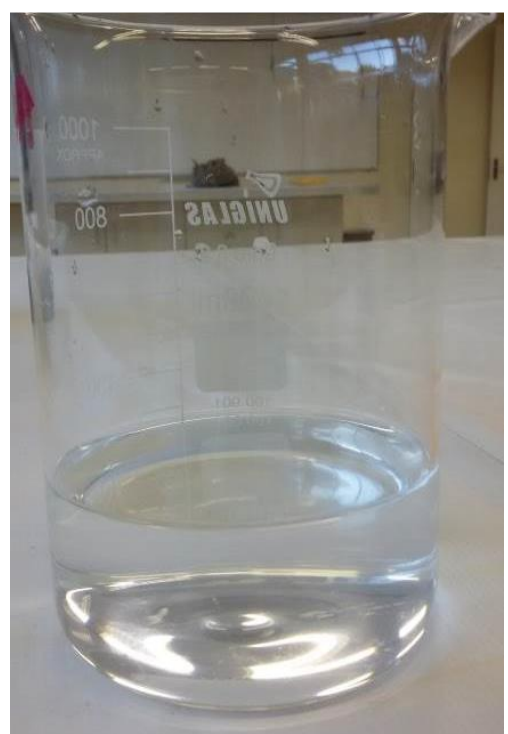

Fonte: Autor (2016).

\section{CONCLUSÃO}

Conforme os resultados analisados, as condições de TDH e agitação do sistema de EC podem influenciar no tratamento de água de processamento de maçãs e as variáveis que apresentaram as maiores eficiências na remoção dos poluentes: MO, DQO, SST, turbidez e cor, foram TDH $=40$ minutos e agitação $=40 \mathrm{rpm}$.

Diante do exposto, a implantação de um sistema de tratamento de EC nas indústrias da cadeia produtiva de maçãs, pode estabelecer a sustentabilidade hídrica desses empreendimentos, proporcionando alívio na demanda de água, minimizando os impactos ambientais e os custos de processo.

\section{REFERÊNCIAS}

CAN, O. T. COD removal from fruit-juice production wastewater by el ectrooxidation electrocoagulation and electro-Fenton processes. Desalination and Water Treatment, v. 52, p. 65-73, 2014.

CARPES, V, M. Sistema híbrido de eletrólise e microfiltração para o tratamento de água de processamento de maçãs. 2017. 136 p. Dissertação (Programa de Pós-Graduação em Ciência e Técnologia de Alimentos), Universidade de Passo Fundo, Passo Fundo - RS, 2017. 
CHEN, G. Electrochemical technologies in wastewater treatment. Separation and Purification Technology, v. 38, p. 11-41, 2004.

MATILAINEN, A.; VEPSÄLÄINEN, M.; SILLANPÄÄ, M. Natural organic matter removal by coagulation during drinking water treatment: A review. Advances in Colloid and Interface Science, v. 159, p. 189-197, 2010.

MERZOUK, B.; MADANI, K.; SEKKI, A. Using electrocoagulation-electroflotation technology to treat synthetic solution and textile wastewater, two case studies. Desalination, v. 250, p. 573-577, 2010.

MOLLAH, M. Y. A.; MORKOVISKY, P.; GOMES, M. K.; KESMEZ, M.; PARGA, J.; COCKE, D. L. Fundamentals, present and future perspectives of electrocoagulation. Journal of Hazardous Materials, v. B114, p. 199-210, 2004.

RAJKUMAR, D.; PALANIVELU, K. Electrochemical treatment of industrial wastewater. Journal of Hazardous Materials, v. B113, p. 123-129, 2004.

TANNERU, C. T.; CHELLAM, S. Mechanisms of virus control during iron electrocoagulation e microfiltration of surface water. WaterResearch, v. 4 6, p. 2011-2120, 2012.

XU, W.; YUE, Q.; GAO, B.; DU, B. Impacts of organic coagulant aid on purification performance and membrane fouling of coagulation/ultrafiltration hybrid process with different Al-based coagulants. Desalination, v. 363, p. 126-133, 2015. 